\title{
DE
}

DE GRUYTER

OPEN

\section{Friend or foe? First language (L1) in second/foreign language (L2/FL) instruction \& Vygotsky}

\author{
Liaquat A. Channa1, Daniel Gilhooly², Charles A. Lynn³, \\ Syed A. Manan ${ }^{1}$, Niaz Hussain Soomro ${ }^{1}$ \\ ${ }^{1}$ Balochistan University of Information Technology, Engineering \& Management \\ Sciences (BUITEMS), Pakistan \\ ${ }^{2}$ University of Central Missouri, Missouri, USA \\ ${ }^{3}$ University of North Carolina, Wilmington, USA. \\ channaliaquat@yahoo.com
}

\begin{abstract}
This theoretical review paper investigates the role of first language (L1) in the mainstream scholarship of second/foreign (L2/FL) language education in the context of language learning, teaching, and bilingual education. The term 'mainstream' refers here to the scholarship that is not informed by sociocultural theory in general and Vygotskian sociocultural theory in particular. The paper later explains a Vygotskian perspective on the use of L1 in L2/FL language education and discusses how the perspective may help content teachers in (a) employing L1 in teaching L2/FL content and (b) helping L2/FL students to become self-regulative users of the target language.
\end{abstract}

Key words: first language; applied linguistics; Vygotsky; sociocultural theory; second/foreign language instruction

\section{Introduction}

Scholars in the field of applied linguistics hold that contexts play a major role in learning a language. While explaining Vygotsky's theory of "scientific" and "spontaneous" concepts, Lantolf and Thorne (2006, p. 294), for instance, stated that learning an FL is dissimilar to learning an L1 in certain respects. He elaborated that unlike an L1, which is learned practically and freely in a natural upbringing, an FL is learned in a controlled and a time-specific classroom environment. Lantolf and Thorne (ibid.) suggested that teacher and the textbooks are, therefore, largely the major sources of FL learning. In addition, a learner is more intentional and goal-directed in FL learning than s/he is in one's L1 learning.

One finds the similar differentiation between the instructional contexts of second language (L2) and FL as has been explained between learning an L1 and an 
FL. Brown (2007, p. 134), for example, stated: "Second language contexts are those in which the classroom target language is readily available. Teaching English in the United States and Australia clearly falls into this (ESL) category. Foreign language contexts are those in which students do not have ready-made contexts for communication beyond their classrooms." These major points of dissimilarity of an L1 from an L2/FL and the peculiarity of contexts in L2 and FL learning propose that FL learning does not have the same settings that L1 or L2 learning usually has. A major implication on the part of FL teachers, therefore, appears to create such controlled learning environments in their classes where learners could learn an FL just as they did their L1.

One may argue that such controlled learning environment, in effect, may amount to be an ideal picture of foreign language instruction. However, because no natural milieu exists for FL learning outside class, the FL teachers largely remain irresolute as to whether or not they should use an L1 in their FL teaching (Holme, 2004). Some teachers do use an L1 in L2/FL classes. However, others believe they should not. The teachers even penalize if their students speak a language other than English in their FL classes.

The teachers' to-do-or-not-to-do position, in effect, appeared interesting to us. Their uncertain position pushed us to investigate how the role of an L1 in FL research and teaching has been theorized and understood. We structure this theoretical review paper as follows: First, we explore what the mainstream literature about language learning, teaching, and bilingual education informs us about the issue. We use the word mainstream to characterize the scholarship that is not informed by sociocultural theory in general and Vygotskian sociocultural theory in particular. We attempt to understand how the Vygotskian sociocultural theory-inspired L2/FL scholarship regards the matter.

\section{L2 or FL?}

Before we discuss the role of an L1 in L2/FL learning, it may be important for the purpose in question to understand at the outset how the scholarship of applied linguistics in general and that of L2/FL in particular differentiate L2 and FL. This shall impact us in how we position ourselves in this paper. As mentioned above, Brown (2007) clearly drew the pedagogical line of difference between L2 and FL learning contexts. However, some scholars have a different perspective about this issue. Kachru (1986; 1990), for instance, theorized the expansion of English all over the world in his model of three circles. The inner circle, he viewed, represents those countries where English is the native language (ENL). United Kingdom (U.K.), United States of America (U.S.A.), Australia, etc. reside in the inner circle. The outer circle, in his model, shows those countries that were British colonies in their past. Sri Lanka, Singapore, Hong Kong, Pakistan, etc. qualify for this circle. 
Kachru conceptualized that English is a second language (L2) in such countries. The expanding circle, he thought, exhibits those countries where English is neither a native language nor the countries had ever been British colonies. China, Saudi Arabia, etc. stand in the expanding circle. He held that English is a foreign language (FL) in such countries.

To us, it seems that applied linguistics research in the area such as World Englishes takes this difference of second and foreign languages into account. However, the scholarship of L2 acquisition considers L2 and FL largely as identical. Discussing this point, for instance, Ortega (2009, p. 5) wrote that "the terms 'L2' or 'second/additional language' may mean the third, fourth, tenth and so on language learned later in life. Thus, these labels should be taken to reflect more of an analytical abstraction made within a disciplinary tradition and less of a black-andwhite reality." In addition, L2 research views, as Ortega mentioned, "the terms mother tongue, first language or L1 generically to refer to the language (in the case of monolingual acquisition) or languages (in the case of bilingual or multilingual acquisition) that a child learns from parents, siblings and caretakers during the critical years of development, from the womb up to about four years of age" (2009, p. 5).

First, since this paper is not directly related to the study of World Englishes, we do not view the distinction between L2 and FL as Kachru did. Second, following Ortega (2009), we see L2 and FL interchangeable as far as the field of L2 research is concerned. Third, we also imply the differentiation, as Brown (2007) did, when we discuss the contexts of pedagogy or classroom instructions. Finally, we take L1 in this paper in the same manner Ortega (2009) did. Now, we explore below how the mainstream literature of language learning has viewed the role of L1 in L2/FL instruction.

\section{The use/role of L1 in the mainstream L2 scholarship}

As we delve into the mainstream scholarship of L2 research, it appears to us that use of an L1 has remained a debatable issue. The matter has remained unsettled because the role of $\mathrm{L} 1 \mathrm{in} \mathrm{L} 2$ research has largely been explored from the vantage point of, what Lantolf and Thorne (2007) termed, "the effects of L1 on L2 production" (p. 219). It has not been looked into how L1 helps learn L2/FL. Thus, depending upon how cognition in general and language in particular have been theorized, different L2 theories have viewed the role of L1 in L2 learning differently.

Behaviorism, for instance, theorized learning including language learning as developing a set of new kind of habits. Mitchell and Myles (1998, p. 23) expounded that behaviorism "stems from work in psychology which saw the learning of any kind of behavior as being based on the notions of stimulus and response. This view 
sees human beings as being exposed to numerous stimuli in their environment... Through repeated reinforcement, a certain stimulus will elicit the same response time and again which will then become a habit". This tradition implied that learning an L2 is developing fresh type of habits. Because old habits of L1 may inhibit the formation of new L2 habits, behaviorism took L1 as interfering with the development of L2. However, behaviorism posited that L2 learning can become easy if the structural systems of L2 matched with those of L1 (Mitchell \& Myles, 1998).

In its pedagogical realization in the shapes of Grammar Translation Method (GTM) and Audio-Lingual Method (ALM), behaviorism underlined excessive target language repetition, mimicry, and role-playing. These processes worked through the mechanism of stimulus, response, and reinforcement. In addition, to examine how L1 interfered and inhibited the path of L2, contrastive analysis was employed as a method in order to learn whether positively or negatively, in what language sub-system(s), and to what extent L1 appeared. The appearance of L1 was considered hindering L2 production. The interference scholarship was based upon error analysis and performance analysis (Brown, 2007; Larsen-Freeman, 2000; Lightbown \& Spada, 1999; Ortega, 2007, 2009; Richards \& Rodgers, 2001; VanPatten, 2007).

Behaviorist views about the use of L1 in L2/FL learning conforms the deficit view of bilingual education. For instance, Baker quoted Laurie, a professor in Cambridge University in the $19^{\text {th }}$ century who argued: "If it were possible for a child to live in two languages at once equally well, so much the worse. His intellectual and spiritual growth would not thereby be doubled, but halved. Unity of mind and character would have great difficulty in asserting itself in such circumstances" (Laurie, 1890, p. 15 in Baker, 2006, p. 143).

In addition to such views, Balance Theory too appeared in bilingual education debate in the context of favoring monolingualism. Conceptualizing language as "a balloon" in mind, the Balance Theory held that "as the second language balloon is pumped higher (e.g. English in the US), so the first language balloon (e.g. Spanish) diminishes in size leading to confusion, frustration, and failure" (Baker, 2006, p. 167). Baker lamented that "Don't raise your child bilingually or problems will result" is still the advice that "parents sometimes receive from well-meaning teachers, doctors, speech therapists, school psychologists and other professionals" (p. 143).

Universal Grammar (UG) theory, as proposed by Chomsky, critiqued the importance of stimulus, response, and reinforcement mechanism as posited by behaviorism. The UG theory criticized the behaviorist stipulation of stimulus as the sole criterion of the emergence of human cognition including language. Commenting on the UG theory, Lightbown and Spada (1999) stated, "According to 
Chomsky, children's minds are not blank slates to be filled merely by imitating language they hear in the environment. Instead, he claims that children are born with a special ability to discover for themselves the underlying rules of a language system" (p. 16). The UG theory, thus, proposed that language learning is a distinctive and separate function of human cognition. There is an innate Language Acquisition Device (LAD) in the human mind that is characterized by its systematicity: universal patterns of linguistic knowledge. Because there is an inherent linguistic systematicity in all the languages of world, L1 has been conceptualized as helping rather than interfering with or hindering L2 learning in the UG theory (Brown, 2007; Larsen-Freeman, 2000; Lightbown \& Spada, 1999; Ortega, 2007, 2009; Richards \& Rodgers, 2001; VanPatten, 2007).

Krashen's monitor theory echoes these voices in the L2 research and L2/FL instruction. Taking the inherent systematicity of linguistic knowledge into account, the monitor theory, therefore, underlines understanding the emergence of meaning rather than putting focus on target language form. The theory holds that "children come to the task of language already knowing a great deal; they simply need the triggering data in the input in order for language acquisition to take place" (VanPatten \& Williams, 2007, p. 17).

Realized for FL pedagogy in the shape of the Natural Approach, the monitor theory did not approach L1 obstructing L2 development. However, the Natural Approach underlined "the exclusive use of target language in the classroom from the beginning levels of instruction" (Hall, 2001, p. 94). The pedagogical approach maintained that "learners would benefit from delaying production until speech 'emerges,' that learners should be as relaxed as possible in the classroom, and that great deal of communication and 'acquisition' should take place, as opposed to analysis" (Brown, 2007, p. 31).

As these theoretical and pedagogical refinements occurred, the theory of bilingual education also reflected these ramifications. Theorists in this area of scholarship moved from the deficit perspective of bilingual education to an enrichment model of bilingual education. For instance, Cummins' $(1980,1981$ in Baker, 2006) "Ice Berg Theory" realized the inherent universal systematicity of linguistic knowledge in his conceptualization of "Common Underlying Proficiency Model (CUPM)." CUPM held that although there were two language systems moving at the surface, there was only one central operating system of common underlying proficiency. Thus, the Ice Berg Theory held that "the same central engine" supports L2 learning rather than hinders it. This central operating system appeared to be Chomsky's Language Acquisition Device (LAD) and the universal linguistic systematicity.

Apart from these two main traditions-behaviorism and UG theory-that held a clear but differing position on the role of L1 in L2 development, some L2 theories 
held a "modest" position on the issue (Ortega, 2007, p. 234). For instance, Ortega stated, "input processing theory currently holds an ambivalent stance because there is no theoretical determination at this point in the development of theory to whether the strategies that learners employ to parse and comprehend the input ought to be considered L1-filtered or guided by linguistic universal knowledge."

Ortega (2007) also discussed that processability theory, skill acquisition theory, and interaction approach either held L1 as slightly influencing L2 learning or took L1 impact for granted in L2 development. She implied that due to the grey and unclear position, processability theory, skill acquisition theory, and interaction approach have not been able to present a well-explained perspective about the role of L1 in L2 learning.

To sum this brief review up, the role of L1 in the mainstream L2 scholarship has been conceptualized at varying levels. However, what is evident at the broader level is that L2 learning and L2/FL pedagogy are explained either through the mechanical mechanism of stimulus, response, and reinforcement; or, they are taken through the perspective of, what Vygotsky termed, "intellectualism and antigeneticism" (Vygotsky, 1987, p. 99). The first view appears in behaviorism, the other in UG theory. In the behaviorist case, an L2/FL teacher has not only to distance his/her students from their L1s but also s/he has to keep them mimicking and repeating the L2/FL. In the UG theory case, while the teacher may see compatibility between the systematicity of L1 and L2/FL systems, the teacher has to have an exclusive use of L2/FL in order to focus upon meaning through understandable input (Lightbown \& Spada, 1999; Ortega, 2009). Whether the L2/FL students and teachers are living and feeling beings of multiple cultures as well as identities, and whether a semiotic tool that is psychological in nature such as one's L1 may help them in their L2/FL learning or teaching, seem to be beyond the purview of these both behaviorism and UG theory (Hall, 2001; Lantolf, 2000; Lantolf \& Thorne, 2006; Newman, Griffin, \& Cole, 1989; Norton, 2000; Smagorinsky, 2011).

In addition, the "stamp of dualism" (Vygotsky, 1987, p. 50) is evident in their debates not only in the context of the role of L1 in L2/FL learning but also in the view of how cognition and language are theorized. Discussing the consequences and implications of such conceptualizations, Vygotsky argued that "intellectual" is generally isolated from "volitional and effective aspects of consciousness" (p. 50). He added, "the inevitable consequence of the isolation of these functions has been the transformation of thinking into an autonomous stream. Thinking itself became the thinker of thoughts. Thinking was divorced from the full vitality of life, from the motives, interests, and inclinations of the thinking individual." Vygotsky, thus, implied human cognition does not only dwell in this domain of pure thinking. He believed human cognition also realized itself as feeling, sensing, seeing, tasting, 
and hearing consciousness. He took human cognition comprehensively believed that it was socio-historical in its quintessence. He held that the consciousness had been learning and advancing historically by the dint of various physical and psychological tools (Smagorinsky, 2011).

Vygotsky's views, therefore, suggested that reducing a dynamic sociocultural L2/FL learner as well as a teacher to decontextualized beings as an ahistorical heap of variables does indeed not offer an explanation of what the role of L1 may be in their L2/FL learning and teaching. In other words, as Lantolf and Thorne (2007) have termed, how "the use of an L1 (may) mediate the learning of the L2" (p. 219) is beyond the dualistic theorizations of human cognition including language in general and L2/FL pedagogy in particular. Before a discussion of how the Vygotskian sociocultural theory-inspired L2 scholarship views the issue of L1 in L2/FL learning, we present below a summary of the major points of Vygotsky's theory in order to contextualize our discussion in question.

\section{Major points of the Vygotskian Sociocultural Theory}

Scholars who work in Vygotskian line of inquiry maintain that Vygotsky witnessed crisis in psychology. The crisis suggested conceptual dualism in ways that human cognition was either theorized from the vantage point of rationalismmind—or empiricism—body (Lantolf \& Thorne, 2006; 2007; Smagorinsky, 2011; Wertsch, 1985). Vygotsky, contrary to rationalism and empiricism, did not hold human behaviour or consciousness as the product of pure acultural reason and intellect or pure unmediated emotions and feelings. He, therefore, rejected behaviorism that approached human cognition in a decontextualized manner and conceptualized human development through the lenses of stimulus, response, and reinforcement. He also critiqued Stern's "intellectualism" (Vygotsky, 1987, p. 99) that held an asocial and unmediated personality/mind as the source of human consciousness. Additionally, he criticized Piaget's "pure empiricism" that theorized cognition through "the pure interaction of consciousness-an interaction that occurs in complete isolation from reality of any consideration of the child's social practice directed toward the mastery of reality" (Vygotsky, 1987, p. 88). Vygotsky, in contrast, took the unity of external-object, reality, mind, etc.and internal-subject, self, body, etc.-and the continuous dialectical interaction of internal and external through the mediation of tools and signs as the source of "cognitive change" (Newman, Griffin, \& Cole, 1989; Smagorinsky, 2011; Vygotsky, 1978; 1987). In other words, Vygotsky viewed the development of human consciousness as the incessant qualitative change that develops and changes dynamically through the mediation of one's self with one's certain cultural signs and tools (Wertsch, 1985). 
The following may summarize the salient features of Vygotsky's theory. First, the roots of human consciousness exist in one's society and culture. Thus, human is sociocultural in its genesis. Second, human consciousness develops dynamically. It is, therefore, not linear, clear, and direct in its orientation. It is dialectic in that it affects and it is simultaneously affected. Third, this dialectic human consciousness originates from human's elementary mental functions-“characterized by control by the natural environment, an absence of conscious realization, (and) individual origins" - to his/her higher mental functions in which one has "voluntary control and conscious realization" (Wertsch, 1985, p. 27). This ceaseless qualitative shift, fourth, occurs through the mediation of tools and signs that are also sociocultural in their nature. Finally, this qualitative change, subsequently, enables a human being to self-regulate, master the surrounding environment, and produce qualitative changes in one's environment, including tools and signs (Smagorinsky, 2011; Vygotsky, 1978; 1987; Wertsch, 1985).

Vygotsky did not perceive human cognition as being separate from human language as Chomsky did. He also did not hold human cognition including language learning as the formation of habits as behaviorism did. In contrast, he viewed language learning as a general human developmental activity that is perpetually mediated by various explicit and implicit tools and signs (Lantolf \& Appel, 1994; Lantolf, 2000; Lantolf \& Thorne, 2006; 2007). This position, as a result, allows us to view the role of $\mathrm{L} 1 \mathrm{in} \mathrm{L} 2 / \mathrm{FL}$ learning and instruction in a special way.

In addition to approaching the role of L1 in a unique way, Vygotskian perspective allows the perception of the L2/FL teacher and student as living beings who are situated and embedded within their cultures. Thus, the teacher and student appear to be complex sociocultural individuals who exist beyond the neutral theorizations of variables of the mainstream L2 scholarship (Norton, 2000). Because Vygotsky implicated his theoretical underpinnings with classroom instruction (Vygotsky, 1978; 1987), we shall briefly discuss below how the L2/FL scholarship inspired by Vygotskian Sociocultural Theory regards the role of L1 in L2/FL learning.

\section{The role of $L 1$ in L2/FL learning and teaching}

L2 research that is informed by Vygotskyian sociocultural theory considers the use of L1 in affirmative terms. While scholars who work in this line of inquiry agree that the ultimate objective of L2/FL instruction is to enable an L2/FL speaker to self-regulate in L2/FL, they approach L1 as playing a helpful role in one's being self-regulative in L2/FL (Hall, 2001; Holme, 2004; Lantolf \& Appel, 1994; Lantolf, 2000; Lantolf \& Thorne, 2006; 2007; Lantolf \& Poehner, 2008). Discussing the role of L1 in various L2 theories, for instance, Ortega (2007) stated, "L1 takes on a unique and positive role in Vygotskian sociocultural theory" (p. 234). She added 
that the use of L1 is theorized as a "mediational tool" in this perspective which the L2/FL learners use voluntarily "to achieve self-regulation and to enable to collaborative engagement in L2 learning events on occasions when using the L2 for higher-level mental activity would be developmentally pre-mature" (p. 235).

Since the L2/FL learners are always with their L1s, Lantolf and Thorne (2007) further suggested "L1 meanings continue to have pervasive effect in the L2 learning" (p. 219). They added that because L1 helps learners not only to communicate with people in their various natural settings but also helps them to "regulate [their] cognitive processes," they must depend upon their L1 "in order to mediate their learning of the L2" (p. 219). How this position may have potential implications for L2 instruction in general and for FL instruction in particular will be related in the following discussion in two ways: (a) the potential of L1 in developing intersubjectivity in L2/FL instruction, (b) the potential mediational role of L1 in content-based instruction in L2/FL contexts.

Discussing the challenges of teaching English in foreign language instructional contexts, Brown (2007) observed that because the use of English is often confined to the boundaries of a classroom, it becomes very challenging for teachers to make their teaching meaningful. In other words, he implied that English as a foreign language (EFL) teachers generally struggle in showing the "relevance of learning English" to their students in certain foreign language learning situations. EFL instruction, thus, usually runs the risk of "intrinsic motivation" on the part of students (p. 135). While the issue of the intrinsic motivation-the fundamental inspiration imbued with teaching that instigates students to learn-of EFL learners may be the result of many factors in such foreign language situations, EFL teachers' not using L1 as a mediational tool or not allowing students to use their L1 to mediate their learning in various classroom events may, we contend, be a complication to the students' learning process.

That is to say, the origins of intrinsic motivation may be rooted in the sociocultural classroom environment including teachers' language learning beliefs shaped by their sociocultural backgrounds. Their beliefs appear typically in the shape of irrelevant and excessive repetition. In addition, their beliefs perform in their unexamined and meaningless pressure upon students to employ the target language for the incomprehensible negotiation of meaning in target language communicative events. While taking this crucial fact into account that the definitive purpose of L2/FL instruction is to facilitate L2/FL learner to be selfregulative in L2/FL (Lantolf \& Thorne, 2006; 2007), the futile uses of target language in FL classrooms may indeed dialectically lead to the birth of intrinsic demotivation among students. In other words, to use Wertsch's $(1985$, p. 158) concept, the "properties of interpsychological plane" of an FL classroom would 
arguably not "make possible the transition to the intrapsychological plane" of L2/FL learners.

This situation indeed directly implicates to the development of "intersubjectivity" in FL classrooms (Wertsch, 1985, pp. 158-183). Wertsch defined intersubjectivity in terms of having a certain level of shared understanding among participants in a certain goal-directed activity. He related this idea to his conception of "situation definition" on the part of both expert and novice in order to allow them to examine and explain how an interpsychological plane functioned (p. 161). He held that a perfect level of intersubjectivity comes into being when a novice defines situation as expected by an expert and vice versa. Wertsch implicated this activity with the crucial role of expert and his/her communication in such situation definitions: "zones of proximal development" (Vygotsky, 1978; 1987).

Wertsch (1985) implied that the lack of having/developing intersubjectivity at an expected level in any goal-directed activity might hinder the actualization of goals of the activity. He maintained that because the primary objective of any instructional event and activity on the part of an expert-teacher-is to enable the novice's transition from interpsychological level to intrapsychological level, it becomes compulsory on the part of the expert to have a certain type of "communication" or "semiotically mediated 'negotiation'." He argued that this communication "must be grounded in context-bound signs" to make this shift happen (p. 161).

In other words, because the expert-an L2/FL teacher in our case-wants the novice-an L2/FL learner-to define the situation of any classroom activity, it becomes important on the part of the expert to use L1 that is the novice's "contextbound sign" in order to develop a certain level of intersubjectivity with novice in the dialectical process of defining situation to support the novice in attempting to achieve the ideal self-regulative L2/FL learner status (Wertsch, 1985, pp. 158183). L1 may, therefore, be used in defining L2 instructional situations to a certain extent in order to develop a shared understanding between the students and the teacher. To sum this up, from the Vygotskian perspective, the use of L1 by an FL/L2 teacher may facilitate him/her not only to reduce the risk-level of his/her Fl/L2 students' demotivation but also s/he can be an explicit mediator by employing an L1 to a certain level to help learners to attain to ideal/expected L2/FL learner state.

Taking into account the issue of demotivation in FL classes, we discuss now how the use of L1 may play the mediational role to a certain level in content-based instruction. By content-based instruction, we mean the L2/FL bilingual classroom where the technical content such as science, mathematics, etc. is taught in L2/FL medium (Gibbons, 2002; Fang \& Schleppegrell, 2008). Fang and Schleppegrell 
(2008) discussed the challenges that ESL/EFL content-area teachers often face when they ask their students to read and understand the textbooks of mathematics, science, history, and literature courses. These textbooks are generally in the English language in both L2 and FL contexts. Explicating the characteristics of the language that is used in such content books, Fang and Schleppegrell showed that the language used in these books is abstract, dense, complex, and detached from daily-life use; the language appears in diverse and abstruse genres. Because the ultimate purpose of such content-based instruction is to enable students to comprehend the concepts of such content and participate in classroom activities, teachers struggle when they teach the content books. On the one hand, the teachers are required to teach this content in such a language that is not the L1 of students, and, on the other hand, they need to teach abstract concepts of the content courses. Indeed, the large part of their struggle in teaching such technical content is with their ESL/EFL students' failure to comprehend textbooks of the content subjects. Fang and Schleppegrell (2008), thus, observed that students "find such texts challenging"; and consequently, they "avoid reading them" (p. 18).

These issues, we consider, directly link to what Vygotsky discussed in his theory of "scientific" and "spontaneous" concepts (Vygotsky, 1987, pp. 167-241). Vygotsky elaborated on the differences between these two types of concepts and related the difference to such instructional practices by drawing an analogy between learning an L1 and an FL. Vygotsky suggested that one learns the "spontaneous concepts," as one learns the native language, unintentionally and practically by participating into various natural activities without being consciously aware. This is usually a "blow to above" process that includes one's reaching an intrapsychological plane from that of an interpsychological one. On the contrary, because the "scientific concepts" are abstract, dense, objective, and complex, one learns them intentionally and consciously. Vygotsky stated, "scientific concepts develop differently than everyday concepts" (p. 171). It is, therefore, an "above to below" procedure. Vygotsky discussed that although scientific and everyday concepts may have "opposite paths" (217), they are mutually interdependent. He argued that while the critical purpose of schoolbased instruction or pedagogy is to develop scientific concepts in students, their successful growth requires not only a teacher but also the intermingling of both of these types of concepts on the part of the teacher in his/her instruction in order to make students' qualitative shift possible from an interpsychological level to an intrapsychological one (Smagorinsky, 2011; Wertsch, 1985).

The theory of "scientific" and "spontaneous" concepts and its suggestions appear to have two major implications for the purpose in question. First, although the expected purpose of the content-based instruction is to enable the L2/FL 
learners to comprehend content in addition to understanding the language in which the content is embedded, the content-area teachers of L2 and FL contexts may largely perform successfully in their instruction if they also intermingle their conceptual instruction with their students' "funds of knowledge" - the everyday knowledge base developed by the students' sociocultural worlds (Moll et al., 1992). The second implication, which is related to the first one, is that because students' L1s are the major intangible sources and mediators in which their "funds of knowledge" are collectively stored and shared, so teachers' conceptual/contentbased instruction may greatly benefit the students if the teachers also employ their students' L1s as mediational tools to a certain extent in their instruction. That is, the Vygotskian perspective allows teachers to mediate their students' conceptual learning by utilizing their L1s as a mediational tool at a certain level in order to support them become self-regulative L2/FL learners and users. This inference, indeed, comes with a crucial theoretical implication on the part of, particularly, the teachers of FL contexts. Teachers are undoubtedly required to maintain a fine and clear line between their successful content-area instruction in English and using L1 only as a mediational tool to a certain extent in such instruction (Lantolf \& Thorne, 2006; 2007).

To sum this part up, the Vygotskian perspective approaches the role of L1 in L2/FL instruction in a clear and positive way. The standpoint not only helps to develop intersubjectivity between students and teachers, thus has the potential to reduce demotivation in $\mathrm{L} 2 / \mathrm{FL}$ classrooms, but can also play the role of a mediational tool to facilitate the L2/FL learners in grasping difficult concepts within technical subjects.

\section{Conclusion}

This theoretical review paper looked into how the role of an L1 is theorized and understood in the mainstream scholarship of language learning and teaching and how the Vygotskian sociocultural theory-inspired L2/FL scholarship regards the role of L1. Unlike the mainstream theories of language learning and teaching whose position on the role of L1 in L2/FL research and instruction varies from interfering to creating ambiguity (Ortega, 2007; VanPatten \& Williams, 2007), Vygotskian sociocultural theory-informed L2/FL scholarship approaches it in a constructive and supporting manner (Lantolf \& Thorne, 2006; 2007). The Vygotskian perspective not only conceptualizes L1 as a mediational tool but also handles L1 in dynamic ways that fundamentally allow an L2/FL learner to grow dialectically and become a self-regulative L2/FL learner and user. The scholarship, thus, regards the use of L1 in L2/FL classrooms as playing the role of reducing demotivation, developing intersubjectivity, and helping both L2/FL teachers to conduct concept/content-based instruction and students to understand and 
internalize such instruction effectively and become successful L2/FL learners. Holme's following words (2004, p. 209) might sum up the Vygotskian perspective on L1 that: "A first language furnishes the learner with strategies through which to consider how they are building the second. Because our learning goal, language, has been naturally evolved, this does not imply that the strategies used to reach it solely natural and unconscious also. Language provides us with the means to think about language. To deny this is to limit our semiotic capability. A first language allows us an opportunity consciously to represent the meaning of a second. To deny ourselves this semiotic opportunity is to deny ourselves the possibilities that language afford us."

\section{References}

Baker, C. (2006). Foundations of bilingual education and bilingualism. Buffalo: Multilingual Matters.

Brown, H. D. (2007). Teaching by principles: An interactive approach to language pedagogy ( $3^{\text {rd }}$ Ed.). New York: Pearson Education.

Fang, Z., \& Schleppegrell, M. J. (2008). Reading in secondary content areas: A language-based pedagogy. Ann Arbor: The University of Michigan Press.

Gibbons, P. (2002). Scaffolding language, scaffolding learning: Teaching second language learners in mainstream classrooms. Portsmouth, NH: Heinemann.

Hall, J. K. (2001). Methods for teaching foreign languages: Creating a community of learners in the classroom. New Jersey: Merill Prentice Hall.

Holme, R. (2004). Mind, metaphor and language teaching. New York: Palgrave.

Kachru, B. B. (1986). The alchemy of English: the spread, functions, and models of non-native Englishes. Oxford: Pergamon Press.

Kachru, B. B. (1990). World Englishes and applied linguistics. Studies in Linguistic Sciences, 19, 127-152.

Lantolf, J. P.; \& Appel, G. (Eds.). (1994). Vygotskyian approaches to second language research. Norwood, NJ: Ablex.

Lantolf, J. P., \& Thorne, S. L. (2006). Sociocultural theory and the genesis of second language development. Oxford: Oxford University Press.

Lantolf, J. P., \& Thorne, S. L. (2007). Sociocultural theory and second language learning. In B. VanPatten \& J. Williams (Eds.). Theories in second language acquisition: An introduction (pp. 201 - 224). Mahwah, New Jersey: Lawrence Erlbaum Associates.

Lantolf, J. P., and Poehner, M. E. (Eds.). (2008). Sociocultural theory and the teaching of second languages. Oakville: Equinox.

Larsen-Freeman, D. (2000). Techniques and principles in language teaching $\left(2^{\text {nd }}\right.$ Ed.). New York: Oxford University Press. 
Lightbown, P. M., \& Spada, N. (1999). How languages are learned (2nd Ed.). New York: Oxford University Press.

Mitchell, R., \& Myles, F. (1998). Second language learning theories. New York: Oxford University Press.

Moll, L. C., Amanti, C., Neff, D., \& Gonzalez, N. (1992). Funds of Knowledge for Teaching: Using a Qualitative Approach to Connect Homes and Classrooms. Theory into Practice, Volume XXXI, Number 2: 132-141.

Newman, D., Griffin, P., \& Cole, M. (1989). The construction zone: Working for cognitive change in school. New York: Cam-bridge University Press.

Norton, B. (2000). Identity and language learning: Gender, ethnicity and educational change. New York: Pearson Education.

Ortega, L. (2007). Second language learning explained? SLA across nine contemporary theories. In B. VanPatten and J. Williams (Eds.). Theories in second language acquisition: An introduction (pp. 225 - 250). Mahwah, New Jersey: Lawrence Erlbaum Associates.

Ortega, L. (2009). Understanding second language acquisition. London, UK: Hodder Education.

Richards, J., \& Rodgers, T. (2001). Approached and methods in language teaching (2nd Ed.). Cambridge, UK: Cambridge University Press.

Smagorinsky, P. (2011). A Vygotskyian framework for literacy research. Bonston: Sense Publishers.

VanPatten, B., \& Williams, J. (2007). Introduction: The nature of theories. In B. VanPatten \& J. Williams (Eds.). Theories in second language acquisition: An introduction (pp. 01-16). Mahwah, New Jersey: Lawrence Erlbaum Associates. VanPatten, B. (2007). Input processing in adult second language acquisition. In B. VanPatten \& J. Williams (Eds.). Theories in second language acquisition: An introduction (pp. 115 - 135). Mahwah, New Jersey: Lawrence Erlbaum Associates.

Vygotsky, L. S. (1934/1987). Thinking and speech. In L. S. Vygotsky, Collected works (Vol. 1, pp. 39-285) (R. Rieber \& A. Carton, Eds.; N. Minick, Trans.). New York: Plenum.

Vygotsky, L. S. (1978). Mind in society: The development of higher psychological processes (M. Cole, V. John-Steiner, S. Scribner, \& E. Souberman, Eds.). Cambridge, MA: Harvard University Press.

Wertsch, J. V. (1985). Vygotsky and the social formation of mind. Cambridge, MA: Harvard University Press. 


\section{Contacts}

Dr. Liaquat A. Channa, Associate Professor, Department of English, Balochistan University of Information Technology, Engineering \& Management Sciences (BUITEMS), Quetta, Balochistan Pakistan channaliaquat@yahoo.com

Dr. Daniel Gilhooly, Professor of Reading and Literacy Program Coordinator Educational Foundations \& Literacy, College of Education, University of Central Missouri, Missouri, USA. gilhooly@ucmo.edu

Dr. Charles A. Lynn, Assistant Professor, Department of Instructional Technology, Foundations, and Secondary Education, Watson College of Education, University of North Carolina, Wilmington, USA.

lynna@uncw.edu

Dr. Syed A. Manan. Assistant Professor, Department of English, Balochistan University of Information Technology, Engineering \& Management Sciences (BUITEMS), Quetta, Balochistan Pakistan Rm_manan@yahoo.com

Dr. Niaz Hussain Soomro, Department of English University of Balochistan, Quetta soomroniaz9@gmail.com 